\title{
CERT Resilience Management Model- Mail-Specific Process Areas: Mail Induction (Version 1.0)
}

\author{
Julia H. Allen \\ Gregory Crabb (United States Postal Inspection Service) \\ Pamela D. Curtis \\ Nader Mehravari \\ David W. White (formerly with the SEI)
}

August 2014

TECHNICAL NOTE

CMU/SEI-2014-TN-010

CERT Division

http://www.sei.cmu.edu 
Copyright 2014 Carnegie Mellon University

This material is based upon work funded and supported by USPS under Contract No. FA8721-05-C0003 with Carnegie Mellon University for the operation of the Software Engineering Institute, a federally funded research and development center sponsored by the United States Department of Defense.

Any opinions, findings and conclusions or recommendations expressed in this material are those of the author(s) and do not necessarily reflect the views of USPS or the United States Department of Defense.

This report was prepared for the

SEI Administrative Agent

AFLCMC/PZM

20 Schilling Circle, Bldg. 1305, 3rd floor

Hanscom AFB, MA 01731-2125

NO WARRANTY. THIS CARNEGIE MELLON UNIVERSITY AND SOFTWARE ENGINEERING INSTITUTE MATERIAL IS FURNISHED ON AN "AS-IS” BASIS. CARNEGIE MELLON UNIVERSITY MAKES NO WARRANTIES OF ANY KIND, EITHER EXPRESSED OR IMPLIED, AS TO ANY MATTER INCLUDING, BUT NOT LIMITED TO, WARRANTY OF FITNESS FOR PURPOSE OR MERCHANTABILITY, EXCLUSIVITY, OR RESULTS OBTAINED FROM USE OF THE MATERIAL. CARNEGIE MELLON UNIVERSITY DOES NOT MAKE ANY WARRANTY OF ANY KIND WITH RESPECT TO FREEDOM FROM PATENT, TRADEMARK, OR COPYRIGHT INFRINGEMENT.

This material has been approved for public release and unlimited distribution except as restricted below.

Internal use:* Permission to reproduce this material and to prepare derivative works from this material for internal use is granted, provided the copyright and "No Warranty" statements are included with all reproductions and derivative works.

External use:* This material may be reproduced in its entirety, without modification, and freely distributed in written or electronic form without requesting formal permission. Permission is required for any other external and/or commercial use. Requests for permission should be directed to the Software Engineering Institute at permission@sei.cmu.edu.

* These restrictions do not apply to U.S. government entities.

Carnegie Mellon ${ }^{\circledR}$ and CERT® are registered marks of Carnegie Mellon University.

DM-0001549 


\section{Table of Contents}

$\begin{array}{lr}\text { Abstract } & \text { iii } \\ \text { Introduction } & \mathbf{3} \\ \text { Mail Induction } & 3 \\ \text { Purpose } & 3 \\ \text { Outline } & 4 \\ \text { Introductory Notes } & 6 \\ \text { Related Process Areas } & 7 \\ \text { Summary of Specific Goals and Practices } & 7 \\ \text { Specific Practices by Goal } & 7 \\ \text { MI:SG1 Establish Standards for Mail Induction } & 13 \\ \text { MI:SG2 Induct Mail } & 21 \\ \text { MI:SG3 Manage Risks to Mail During Induction } & 24 \\ \text { MI:SG4 Control Mail During Induction } & 34 \\ \text { MI:SG5 Manage Mail Discrepancies During Induction } & 38 \\ \text { Mail Induction Process Area References } & 40 \\ \text { References } & 3\end{array}$ 
CMU/SEI-2014-TN-010 | ii 


\begin{abstract}
Developing and implementing measurable methodologies for improving the security and resilience of a national postal sector directly contribute to protecting public and postal personnel, assets, and revenues. Such methodologies also contribute to the security and resilience of the mode of transport used to carry mail and the protection of the global mail supply chain. Since 2011, the U.S. Postal Inspection Service (USPIS) has collaborated with the CERT $^{\circledR}$ Division at Carnegie Mellon University's Software Engineering Institute (SEI) to improve the resilience of selected U.S. Postal Service (USPS) products and services. The CERT Resilience Management Model (CERT-RMM) and its companion diagnostic methods served as the foundational tool for this collaboration.

This report includes one result of the USPIS/CERT collaboration. It is an extension of CERTRMM to include a new mail-specific process area for the induction (acceptance) of mail into the U.S. domestic mail stream. The purpose is to ensure that mail is collected and accepted in accordance with USPS standards and requirements for the resilience of mail during the induction process.
\end{abstract}


CMU/SEI-2014-TN-010 | iv 


\section{Introduction}

In December 2011, the U.S. Postal Inspection Service (USPIS) asked CERT staff to develop new mail-specific process areas (PAs) to manage the resilience of mail throughout its lifecycle-from induction to delivery. The initial scope of this effort included mail acceptance, revenue confirmation, mail security, mail transport, and mail custody.

The CERT ${ }^{\circledR}$ Resilience Management Model (CERT-RMM) [Caralli 2011], which was developed by the CERT Division at Carnegie Mellon University's Software Engineering Institute (SEI), and its companion diagnostic methods served as the foundational tool for this collaboration. CERT-RMM is a capability-focused maturity model for improving an organization's management of operational resilience activities across the domains of security management, business continuity management, and aspects of information technology operations management. These improvements enable high-value services to meet their missions consistently and with high quality, particularly during times of stress and disruption.

The USPIS objectives for this project included the following [Crabb 2012, Joch 2013]:

- Define common criteria for assuring that U.S. Postal Service (USPS) products are resilient.

- Evaluate business partners and customer operations in their handling of mail.

- Use these new PAs in conjunction with other selected CERT-RMM PAs to evaluate new and existing USPS products, services, suppliers, and partners, in terms of their security and resilience.

- Assure that each product's contribution to USPS revenue is commensurate with services delivered.

- Identify revenue collection gaps more quickly.

The development project commenced in January 2012 and was an active collaboration between USPIS subject matter experts and CERT staff. The architecture of the mail-specific PAs follows that of the existing 26 PAs described in CERT-RMM. The scope and content of these PAs evolved significantly during the course of the development project. In July 2012, initial outlines for four mail-specific PAs-Mail Induction (MI), Mail Revenue Assurance (MRA), Mail Transportation (MT), and Mail Delivery (MD)-were accepted by the USPIS, as well as an initial draft of the MRA PA.

The PAs specific to the induction of mail and to mail revenue assurance were pilot tested extensively during the Express Mail projects described in an SEI technical note titled Improving the Security and Resilience of U.S. Postal Service Mail Products and Services Using the CERT Resilience Management Model [Crabb 2014]. In April 2013, outlines for all four mail-specific PAs were accepted as baselined by the USPIS, and in July 2013, baselined versions of two complete PAs, MI and MRA [Allen 2014b], were accepted by the USPIS.

\footnotetext{
(B) CERT is a registered mark of Carnegie Mellon University.
} 
Following this initial effort, the USPIS asked CERT to extend the goals and practices contained within the MT outline for U.S. domestic mail to address international mail transportation. This effort is described in the report titled CERT Resilience Management Model Mail-Specific Process Areas: International Mail Transportation, Version 1.0 [Allen 2014a].

The Mail Induction Process Area is presented in this report. 


\section{Mail Induction}

\section{Purpose}

The purpose of Mail Induction (MI) is to ensure that all mailpieces (mail) are inducted (collected and accepted) in accordance with USPS standards.

\section{Outline}

MI:SG1 Establish Standards for Mail Induction

Standards for mail induction are established and maintained.

MI:SG1.SP1 Establish Standards for Mail Induction

Standards for the induction of mailpieces are identified, established, and maintained.

\section{MI:SG2 Induct Mail}

Induction of mail is established and maintained in accordance with standards.

\section{MI:SG2.SP1 Collect Mail}

Mailpieces are received by the USPS in accordance with standards.

MI:SG2.SP2 Accept Mail

Mailpieces are verified and accepted in accordance with standards.

MI:SG2.SP3 Classify and Prioritize Mail

Mailpieces are classified and prioritized in accordance with standards.

MI:SG2.SP4 Convey Mail to Origin Processing Facilities

Mailpieces are conveyed from their collection location to origin processing facilities in accordance with standards.

\section{MI:SG3 Manage Risks to Mail During Induction}

Operational risks to mail during induction are identified and addressed.

MI:SG3.SP1 Identify and Assess Risks to Mail During Induction

Operational risks to mailpieces during induction are periodically identified and assessed.

MI:SG3.SP2 Address Risks to Mail During Induction

Identified operational risks to mailpieces during induction are addressed.

\section{MI:SG4 Control Mail During Induction}

Controls to protect mail during induction are established and maintained in accordance with standards.

MI:SG4.SP1 Control Availability of Mail During Induction

Controls are established and maintained to assure availability of mailpieces during induction in accordance with standards. 
MI:SG4.SP2 Control Sanctity of Mail During Induction

Controls are established and maintained to assure sanctity of mailpieces during induction in accordance with standards.

MI:SG4.SP3 Control Custody of Mail During Induction

Controls are established and maintained to assure custody of mailpieces during induction in accordance with standards.

MI:SG4.SP4 Control Visibility of Mail During Induction Controls are established and maintained to assure visibility of mailpieces during induction in accordance with standards.

\section{MI:SG5 Manage Mail Discrepancies During Induction}

Discrepancies during the induction of mail are identified and addressed.

MI:SG5.SP1 Establish and Maintain Mail Discrepancy Plans for Induction Plans and procedures for managing mail discrepancies during induction are established and maintained.

MI:SG5.SP2 Identify and Address Mail Discrepancies During Induction Mail discrepancies during induction are identified and addressed in accordance with plans and procedures.

\section{Introductory Notes}

This CERT Resilience Management Model (CERT-RMM) supplemental process area describes key goals and practices that will be used as a standalone evaluation tool or in conjunction with other CERT-RMM process areas to evaluate the resilience of mail during its induction, transportation, and delivery by the USPS.

The resilient management of mail is critical to support the goals of the USPS. It requires identifying and establishing the Domestic Mail Manual (DMM) and Postal Operations Manual (POM) standards that pertain to mail resilience and putting controls in place to ensure that these standards are satisfied throughout the mail lifecycle, from induction to delivery.

Mail is defined as the combination of the classes and types of pieces that are handled by the USPS. A mailpiece is characterized by the following attributes:

- Mail class: The service purchased by the mailer, which defines the required service standard for each mailpiece. Mail class and service level (or service) are synonymous and may be used interchangeably. Mail classes are defined in the DMM and POM and include, for example, Priority Mail Express, Priority Mail, First-Class Mail, Standard Mail, Parcel Post, Media Mail and Library Mail, Periodicals, and Bound Printed Matter [DMM, pp. 6-7; POM 137.42].

- Mail type: Mail types are dependent on size, shape, and weight and include retail mail and commercial (business) mail letters, cards, flats, and parcels. Mail types are defined in the DMM [DMM, pp. 6-7]. 
- Mail extra services are selectively available based on mail class and type. These include [1]

- proof of mailing, proof of delivery, and indemnification for loss or damage. These services include certified mail, registered mail, collect on delivery (COD), insured mail, return receipt, and merchandise return service.

- certificate of mailing, special handling, delivery confirmation, and signature confirmation [POM 137.441, 137.45]

Resilience requirements form the basis for the actions that the USPS takes to protect mail. These requirements are established based on the mail class, type, and extra services and in accordance with defined standards (DMM and POM). The resilience requirements for mail are assigned to each class and type of mail and extra service so that the appropriate type and level of protective controls can be designed, implemented, and monitored to meet the requirements. Resilience requirements for mailpieces include

- availability: the quality of mailpieces being accessible to all authorized citizens in a timely fashion as determined by the mail class. Mail must not be lost, stolen, or unnecessarily delayed.

- sanctity: the quality of mailpieces being inviolate (free from violation or damage; preserved from alteration of original content), intact (untouched by anything that causes harm or diminishes; no relevant component removed or destroyed) [2, 3]. Mailpieces must be kept in the condition intended for the sender and suitable for being transported by the USPS. Certain classes of mail must be protected against unauthorized access, modification, or disclosure.

- custody: the state of mailpieces being in the immediate charge and control of authorized USPS personnel from induction through delivery.

- visibility: the ability to track mail from induction to delivery by integrating electronic mailing documentation, Intelligent Mail barcodes (IMBs) on mailpieces and containers, and in-process scanning while mail is in the postal network [Pub 32].

The induction phase of the mail lifecycle generally starts when mailpieces are picked up or collected from a wide range of locations and entry points. For retail mail, these include retail service counters in USPS facilities (e.g., Post Office, branch, and station), Postal Service lobby drop slots, collection boxes, customer mailboxes, contract post units (CPUs), USPS-approved shipper location, and carrier pickups. For commercial mail, these include business mail entry units (BMEUs) and detached mail units (DMUs).

After collection, mail is verified and accepted at USPS facilities and authorized mail acceptance offices by acceptance personnel in conformance with mail induction standards. Mailpieces are prioritized according to the class, type, and extra services that the mailer has purchased. USPS acceptance personnel are supported by mail acceptance processing equipment and systems, so the presence of such equipment and systems (such as mail scanners) is assumed for all roles and responsibilities that are fulfilled by such personnel. 
Resilience requirements are assigned to mail so that the appropriate type and level of controls can be selected to meet these requirements. Physical, technical, and administrative controls are designed, implemented, and managed, and the effectiveness of these controls is monitored. From the time and location mail is inducted by the USPS to the time and location it is delivered, mail availability, sanctity, custody, and visibility are managed commensurate with mail class, type, and extra services. Risks to mailpieces are identified and assessed, and risks are addressed and monitored. In addition, discrepancies in the induction of mail and to the availability, sanctity, custody, and visibility of mail are identified and addressed.

The MI process area is not intended to replace standards in the DMM or the POM. Instead, MI provides a set of goals and practices that can be scaled and used to assess the maturity and capability of USPS and authorized mailers and induction organizations to satisfy the resilience requirements and standards in the DMM and the POM, as well as resilience requirements from USPS stakeholders.

\section{Related Process Areas}

The identification of mail revenue standards and the assurance of mail revenue (postage affixed, payment, discrepancies, and fraud) are addressed in the Mail Revenue Assurance process area.

Requirements for the receipt of payment are described in the Mail Revenue Assurance process area.

The protection of mail during transportation is addressed in the Mail Transportation process area.

The protection of mail during delivery is addressed in the Mail Delivery process area. Compliance with mail induction standards is addressed in the Compliance process area.

The management of the internal control system that ensures the resilience of mailpieces and mail services during induction is addressed in the Controls Management process area.

The assignment of resilience requirements to the physical facilities where mailpieces are inducted and handled and other physical, environmental, and geographical controls to support the resilience of mailpieces and mail services during induction are managed in the Environmental Control process area.

The establishment and management of controls relating to the integrity and availability of technology assets used for mailpieces and mail services during induction are defined in the Technology Management process area.

The processes to identify and analyze events, detect incidents, and determine an appropriate organizational response for events affecting mailpieces and mail services during induction are addressed in the Incident Management and Control process area. 
The controls to ensure the continuity of essential operations of mail services if a disruption occurs during induction as a result of an incident, disaster, or other disruptive event are addressed in the Service Continuity process area.

Ensuring that resilience requirements for mailpieces are met by contractors and other external entities involved during induction is addressed in the External Dependencies Management process area.

Controls to manage the performance of people in support of the resilient management of mailpieces during induction are addressed in the Human Resource Management process area.

Inventories and gap analysis of skills required for the resilient management of mailpieces during induction are addressed in the Human Resource Management process area.

The provision of awareness and training to staff necessary for the resilient management of mailpieces during induction is addressed in the Organizational Training and Awareness process area.

\section{Summary of Specific Goals and Practices}

MI:SG1 Establish Standards for Mail Induction MI:SG1.SP1 Establish Standards for Mail Induction

MI:SG2 Induct Mail MI:SG2.SP1 Collect Mail MI:SG2.SP2 Accept Mail MI:SG2.SP3 Classify and Prioritize Mail MI:SG2.SP4 Convey Mail to Origin Processing Facilities

MI:SG3 Manage Risks to Mail During Induction MI:SG3.SP1 Identify and Assess Risks to Mail During Induction MI:SG3.SP2 Address Risks to Mail During Induction

MI:SG4 Control Mail During Induction MI:SG4.SP1 Control Availability of Mail During Induction MI:SG4.SP2 Control Sanctity of Mail During Induction MI:SG4.SP3 Control Custody of Mail During Induction MI:SG4.SP4 Control Visibility of Mail During Induction

MI:SG5 Manage Mail Discrepancies During Induction MI:SG5.SP1 Establish and Maintain Mail Discrepancy Plans for Induction MI:SG5.SP2 Identify and Address Mail Discrepancies During Induction

\section{Specific Practices by Goal}

\section{MI:SG1 Establish Standards for Mail Induction}

Standards for mail induction are established and maintained.

The purpose of establishing standards, policies, operating procedures, and other specifications (standards for short) for mail induction is to ensure that mailers (including service providers) understand their responsibilities for preparing mail for induction and that 
USPS personnel understand their responsibilities for collecting and accepting mail into the mailstream. Such standards also provide the foundation for protecting mailpieces during induction.

To ensure that mailpieces are adequately protected during induction, standards specify resilience requirements that are assigned to mailpieces based on their class, type, and extra services. Thus standards for the availability, sanctity, custody, and visibility of mail must be established and maintained. The specification of resilience requirements in mail induction standards support the design, implementation, and monitoring of controls to ensure mailpiece resilience requirements are met (refer to MI:SG4, Control Mail During Induction).

\section{MI:SG1.SP1 Establish Standards for Mail Induction}

Standards for the induction of mailpieces are identified, established, and maintained.

Standards governing what material can be mailed and in what manner it can be mailedand therefore what the USPS can collect and accept for transportation and delivery-are determined by U.S. postal laws and regulations as set forth in the Code of Federal Regulations Title 39 - Postal Service (e-CFR) and are maintained by the USPS Mailing Standards Department. They are published in two manuals, the Domestic Mail Manual (DMM) and the Postal Operations Manual (POM), and three publications, Publication 28 Postal Addressing Standards [Pub 28], Publication 52 Hazardous, Restricted, and Perishable Mail [Pub 52], and Publication 417 Nonprofit Standard Mail Eligibility [Pub 417]. Such standards define mailability-the eligibility of a mailpiece or mailing to be inducted into the mailstream because it meets size, weight, and other preparation criteria and its contents are not prohibited by law as mail [Pub 32].

The DMM is distributed to selected Post Offices, is available online on Postal Explorer [4], and is available for sale by subscription to the public. Notices of revisions to the DMM are published in the Federal Register, the Postal Bulletin [11], and the DMM Advisory, and the DMM is updated periodically with those revisions.

The POM contains general information concerning acceptance of domestic mail and is provided as a guide for use by USPS personnel involved in retail and retail-related services. Its guidelines cross-reference the DMM but do not supersede the rules and regulations contained in the DMM. It is distributed to all Postal Service facilities. Notices of revisions to the POM are published in the Postal Bulletin, and the POM is updated periodically with Postal Bulletin revisions.

Standards specific to the collection and acceptance of mailpieces and for the availability, sanctity, custody, and visibility of mailpieces are described below.

Compliance obligations that may result in or form the basis for mail induction standards are identified and managed in the Compliance process area. 


\section{Collection}

The DMM specifies deposit and collection standards for all classes of mail. These are examples of unique deposit and collection requirements by mail class:

\section{- $\quad$ First-Class Mail}

- Retail: Single-piece First-Class Mail letters and cards may be deposited into any collection box, mail receptacle, or at any place where mail is accepted if the full required postage is paid with adhesive stamps. Metered mail and permit imprint mail must be deposited at the appropriate Post Office [DMM 136].

- Commercial: First-Class Mail paid at Presorted or any automation prices must be deposited at locations and times designated by the postmaster. Metered mail must be deposited in locations under the jurisdiction of the licensing Post Office. USPS may collect Presorted First-Class Mail and automation First-Class Mail at a mailer's facility if part of an approved collection service for other classes of mail; space is available on the transportation required for those classes; and [DMM 236]

- acceptance and verification are done at the customer's facility; or

- postage is paid with permit imprint under an optional procedure; or

- postage is paid with meter or precanceled stamps.

- Priority Mail

- Retail: Priority Mail weighing 13 ounces or less may be deposited into any collection box, mail chute, or mail receptacle or at any place where mail is accepted if the full required postage is paid with adhesive stamps. Metered mail must be deposited in locations under the jurisdiction of the licensing Post Office. Priority Mail weighing more than 13 ounces bearing only postage stamps must be presented to USPS personnel at a retail service counter in a USPS facility [DMM 126].

- Commercial: Mailpieces bearing postage evidencing indicia must be deposited in a collection box (except for mailings of 200 or more Critical Mail letters) or at a postal facility within the ZIP Code shown in the indicia. Pickup on Demand service is available from designated Post Offices [DMM 226].

\section{- Priority Mail Express}

- Retail: Mail weighing more than 13 ounces bearing only postage stamps as postage may not be deposited into a collection box, Postal Service lobby drop, Automated Postal Center (APC) drop, USPS dock, customer mailbox, or other unattended location. These mailpieces are also precluded from pickup service. The sender must present such items to USPS personnel at a retail service counter in a USPS facility. Improperly presented items will be returned to the sender for proper entry and acceptance. The "time and date of mailing" for these items is the time and date when the items are presented and accepted [DMM 116]. 
- Commercial: Commercial mail may be deposited in Express Mail collection boxes, handed to delivery and collection employees during their normal delivery and collection duties, or picked up by USPS Pickup on Demand service. The "time and date of mailing" for items deposited in these ways is the time and date the items are brought to the Priority Mail Express acceptance unit [DMM 216].

The POM specifies collection standards for specific classes of mail. One example is Priority Mail Express, which includes [POM 137.542, 137.552, 137,562]

- presentation at designated postal facilities, Priority Mail Express collection boxes, pickup services

- ensuring that the mailpiece has an appropriate label, correct postage, and that the ZIP Code supports next day delivery (verification)

- returning the mailpiece to the mailer if verification is not successful

The POM also specifies requirements for mail collection boxes (appearance, number and types, locations, removal and relocation, and records of scheduled collections) [POM 315] and types of collection boxes (residential, business area, arterial boxes on major traffic thoroughfares, and Priority Mail Express) [POM 32].

The Glossary of Postal Terms [Pub 32] provides definitions of all mail deposit and collections terms that are used in the DMM and POM.

\section{Acceptance}

The DMM specifies verification and acceptance standards for all types and classes of mail. These standards pertain to

- dimensions and weights

- elements on the face of mailpieces

- addressing

- packaging and containers

- nonmailable matter, including certain dangerous and hazardous goods

- postage affixed, labels, and barcodes

- forms, permits, and documentation

- signatures

- $\quad$ prices, fees, and payment methods

- quantity and bundling

These standards serve as instructions for mailers and as guidance for USPS personnel by which to judge whether mailpieces are acceptable.

Postmasters and other managers of postal facilities must prominently display in Post Office lobbies, acceptance areas, and at self-service postal centers a notice to mailers about prohibitions and requirements related to dangerous materials [POM 139.112). Posters describing characteristics of potentially dangerous mail are also prominently displayed in 
postal facilities. Dangerous and hazardous mail are treated as discrepancies as described in MI:SG5, Manage Mail Discrepancies During Induction.

\section{Availability}

Standards governing mail availability are specified in the DMM, the POM, and the Administrative Support Manual [ASM 2012]. For example, the ASM contains standards relating to losses, robberies and burglaries, protection of mail against theft during collection and delivery, detention of mail, facility security, and qualifications of personnel. The POM contains standards relating to access to mail and mail handling areas [POM 137.71], indemnity claims, and sealing of mail containers.

Mail availability is also governed by statutes in 18 USC Sections 1691-1737 that protect the mail from theft, obstruction, and interference [13] and by service standards specified in Title 39 Part 121. The Universal Postal Union (UPU) publication S58, Postal security standards General security measures, specifies that access to mail must be restricted as appropriate to postal service personnel or authorized contractors with mail handling responsibilities [UPU 2012 Part A, 8.1.2, pg. 15]. The UPU standard also specifies standards for transportation and conveyance security and for personnel integrity [UPU 2012].

\section{Sanctity}

Standards governing mail sanctity are defined in Section 274 of the Administrative Support Manual [ASM 2012]. ASM 274.1 states "The Postal Service must preserve and protect the security of all mail in its custody from unauthorized opening, inspection, or reading of contents or covers; tampering; delay; or other unauthorized acts."

An exception is ASM 211.31, which permits the Office of Inspector General (OIG) and the U.S. Postal Inspection Service (USPIS) personnel to access mail that might be relevant to an official audit or investigation. Also, personnel of the Mail Recovery Unit may, without a warrant, read mail to try to determine where to return it.

ASM 271.63 states that "Employees must not place mail in their pockets or clothing, in their lockers or desks, or in any other personal receptacles." POM 632.6 covers protection of mail delivered to mail receptacles in apartment houses.

Courts have long held that the fourth amendment of the Constitution of the United States applies to mail: "The right of the people to be secure in their persons, houses, papers, and effects, against unreasonable searches and seizures, shall not be violated, and no Warrants shall issue, but upon probable cause, supported by Oath or affirmation, and particularly describing the place to be searched, and the persons or things to be seized."

Postal employees may not read the backs of postcards or the contents of mail that opens accidentally in mail processing systems or from other causes, and they may not copy anything from mail content by writing or other method.

The USPS is required by 39 USC 404(c) to "maintain one or more classes of mail for the transmission of letters sealed against inspection" [12]. Mail sanctity is also rooted in various 
statutes in 18 USC Sections 1691-1737, such as Section 1702, "Obstruction of correspondence," regarding taking a mailpiece out of the mailstream to destroy it or to "pry into the business or secrets of another" [13].

UPU publication S58 specifies that access to mail must be restricted as appropriate to postal service personnel or authorized contractors with mail handling responsibilities [UPU PSS Part A, 8.1.2, pg. 15].

Standards for handling mail sanctity discrepancies are found in POM 169.2 (with crossreferences to DMM and ASM), regarding reporting theft of mail from mail receptacles and obstruction, interception, tampering, and rifling of mail.

\section{Custody}

The DMM and POM define custody standards for all classes and types of retail and commercial mail as well as extra services (sometimes designated as accountable mail), which have specific custody and visibility requirements [DMM 503; POM 137.73; POM 137.44].

The following publications provide examples of the additional guidance on custody requirements for accountable mail and extra services:

- Priority Mail Express

- Publication 97 Express Mail Manifesting Business and Technical Guide [Pub 97]

- Quick Service Guide 110 - Retail Letters, Flats, and Parcels [6]

- Quick Service Guide 410 - Commercial Parcels [7]

- Registered Mail: Handbook DM-901 Registered Mail [POM 476.9, pg. 315; HB DM-901]

\section{Visibility}

The DMM and POM define visibility standards for all classes and types of retail and commercial mail as well as extra services (sometimes designated as accountable mail), which have specific visibility requirements [DMM 503; POM 137.73; POM 137.44].

The following publications provide examples of the additional guidance on visibility requirements for accountable mail and extra services:

- Priority Mail Express

- Publication 97 Express Mail Manifesting Business and Technical Guide [Pub 97]

- Quick Service Guide 110 - Retail Letters, Flats, and Parcels [6]

○ Quick Service Guide 410 - Commercial Parcels [7]

- Registered Mail: Handbook DM-901 Registered Mail [POM 476.9, pg. 315; HB DM-901]

Additional standards for the visibility of mail are described in supporting specifications and guidelines for postage and barcodes such as Intelligent Mail Barcode Specification USPS- $B$ 3200 [USPS 2009] and A Guide to Intelligent Mail for Letters and Flats [USPS 2012]. The use of IMbs and Intelligent Mail package barcodes (IMpbs), as well as electronic documentation 
that is submitted by commercial mailers, may provide mailers and the USPS with end-to-end visibility into the mailstream.

\section{Typical Work Products}

1. Standards for collection of mailpieces

2. Standards for acceptance of mailpieces

3. Standards for availability of mailpieces

4. Standards for sanctity of mailpieces

5. Standards for custody of mailpieces

6. Standards for visibility of mailpieces

7. List of federal and state laws relating to mailability and mail induction

8. Procedures for revising standards

9. Procedures for disseminating standards updates

\section{Subpractices}

1. Identify all laws, standards, policies, operating procedures, and supporting specifications and guidelines that affect mailability, mail induction practices, and resilience requirements for mailpieces during induction.

2. Communicate mail induction standards to all affected parties (USPS personnel, acceptance offices, mailers).

3. Develop and publish new standards as needed to reflect changes in mail induction practices.

4. Follow established procedures for revising existing standards.

5. Document approved revisions to existing standards in all affected publications, including cross-references in the POM to the DMM.

6. Communicate changes to mail induction standards to all affected parties (USPS personnel, acceptance offices, mailers).

7. Make standards available to mailers, USPS personnel, and other users of the standards in appropriate locations and formats.

8. Ensure that USPS personnel adhere to standards and verify that mailers adhere to standards.

\section{MI:SG2 Induct Mail}

Induction of mail is established and maintained in accordance with standards.

The induction of mail includes collecting mail from a wide range of deposit and entry points, verifying and accepting mail, classifying and prioritizing mail, and conveying mail to origin 
processing facilities in preparation for transportation (refer to the Mail Transportation process area).

The first steps in the induction of mail occur when USPS personnel collect, verify, and accept a mailpiece. USPS personnel who induct mail serve a highly diverse customer base. It includes individual citizens, small volume mailers who manually prepare their mailings, and medium and high volume mailers who submit mailings containing millions of pieces with complex mail preparation that allows them to take advantage of the lowest available prices. USPS induction personnel assist mailers with mail preparation and acceptance questions, establish payment accounts and transact payment for business mailings, and provide other mailer support functions.

USPS induction personnel classify and prioritize mail based on mail type, class, and extra services requested by the mailer and verify mail preparation and payment to ensure that mail is accepted by the USPS according to the standards associated with that type, class, and service. Verification of adherence to induction standards by USPS personnel is a first line of defense against failure to satisfy resilience requirements during mail transportation and delivery and failure to assure mail revenue.

The DMM defines mail preparation standards for all classes of retail and commercial mail. Mailers must comply with all applicable postal standards. Although USPS induction personnel are responsible for verifying that the mailings presented to them meet the standards for the prices claimed, the burden rests with the mailer to comply with the laws and standards governing domestic mail [DMM 601.1.7, 8.8, 10.5, 10.13.5, 10.17.5]. For mailings that require a postage statement, the mailer certifies compliance with all applicable postal standards when signing the statement [DMM 607.1, pg. 1141].

All international mail, once it enters the United States, is considered domestic mail. A condition of inducting international mail is that it meets customs requirements. The meeting of such requirements, specified in the International Mail Manual and referenced in the DMM [608.2, pg. 1144], is considered out of scope for this process area.

\section{MI:SG2.SP1 Collect Mail}

Mailpieces are received by the USPS in accordance with standards.

Retail and commercial mail is collected by USPS personnel and contractors in face-to-face transactions at Post Offices, stations, branches, CPUs, community Post Offices (CPOs), military Post Offices, BMEUs, associate Post Offices (APOs), DMUs, and periodically even at nonpersonnel units [POM 123]. Mailpieces are also collected through letter collection receptacles and parcel depositories in postal facilities, USPS drop boxes and collection boxes [POM 315, 32, 33] and Priority Mail Express collection boxes, carrier pickup (at homes and businesses, including Priority Mail Express Pickup on Demand service), and authorized shippers. 
To elaborate, mail is collected from wide range of locations and entry points, including the following [Mehravari 2013]:

- Pickup by USPS carriers [Pub 399]

○ carrier pickup service

- pickup on demand service (scheduled and unscheduled)

- Dropoff by mailer

- Outside USPS facilities

- Priority Mail Express collection box

- regular mail collection box

- customer mailbox

- USPS gopost ${ }^{\circledR}$ locations

- handed over to any delivery or collection personnel during their delivery or collection duties

- Inside USPS facilities

- retail service counters at Post Offices, stations, or branches

- unattended drop off locations (for example, Post Office lobby after hours)

- Automated Postal Center drop

- USPS service dock

- contract postal units and authorized shippers (third party)

- community Post Office

- BMEU

- DMU

Refer to MI:SG1.SP1, Establish Standards for Mail Induction, (under Collection) for additional descriptions and examples.

Typical Work Products

1. Collected retail mail

2. Collected commercial (business) mail

3. Discrepancies in collected mail

\section{Subpractices}

1. Collect retail mail in accordance with standards.

2. Collect commercial (business) mail in accordance with standards.

3. Identify discrepancies in collected mail.

Refer to MI:SG5, Manage Mail Discrepancies During Induction, for the handling of discrepancies in collected mail. 


\section{MI:SG2.SP2 Accept Mail}

Mailpieces are verified and accepted in accordance with standards.

Mailpieces are not considered accepted until they arrive at a USPS acceptance facility and are processed and verified by acceptance personnel [POM 137]. Verification of adherence to standards thus involves a variety of conditions, situations, and personnel. (The assignment of resilience requirements to the physical facilities where mailpieces are accepted is addressed in the Environmental Control process area.)

When mail is accepted in a face-to-face transaction at a postal facility, USPS acceptance personnel help mailers prepare mail according to standards, refuse prohibited and improperly prepared mail matter, and ensure that mail is properly marked, endorsed, and paid for. Business mail is checked in upon arrival at an acceptance office and then subjected to a process to verify eligibility, processing category, machinable criteria, postage payment method, postage affixed, and endorsements. Once acceptance personnel have completed the required verification procedures and finalized the postage statement, the business mailing is considered accepted and is cleared to operations for processing or returned to the mailer for direct transportation [DAR 2012, pg. 8].

Business letter and flat-size mailings that fall within certain dimensions may undergo automated acceptance testing on The Mail Evaluation Readability Lookup Instrument (MERLIN). MERLIN measures mailpieces against a number of DMM standards [Pub 430].

Acceptance personnel are required to ensure that all business mail is verified and cleared prior to being loaded onto USPS and approved contractor trucks. This process includes many manual processes, such as sampling, verification of destination labels, verification of proper preparation, a count and comparison of containers against submitted documentation, verification of physically separated and sequenced mailings, and verifying that mail is properly loaded into the truck [DAR, pg. 8].

This practice addresses the verification and acceptance of mail during induction. Practices describing the verification and acceptance of mail during transportation and delivery are described in the Mail Transportation process area and the Mail Delivery process area, respectively.

Typical Work Products

1. Accepted retail and business mail that conforms to standards

2. Verified postage statements

3. Accurate and complete charges against postage payment accounts

4. Acceptance scans

5. Discrepancies in accepted mail 


\section{Subpractices}

1. Assist mailers in preparing mail according to standards.

In face-to-face transactions with mailers, advise mailers on the rules of mail acceptance and assist them in selecting the mail class and packaging that is best suited to their needs.

2. Refuse prohibited and improperly prepared mail matter.

Refuse prohibited mail matter according to the DMM [601.8-10, 601.8.12] and

Publication 52 Hazardous, Restricted, and Perishable Mail [Pub 52].

Refuse mail that is not properly packed, packaged, sealed, addressed, and labeled for safe handling to the designated destination [POM 137.12] in accordance with DMM standards.

Explain the reasons for the refusal to the mailer [POM 139.113].

3. Verify eligibility of the mailpiece for the mail type, class, and extra services requested.

Eligibility is defined in the DMM for retail and commercial mail, cards, flats, and parcels. It includes, for example, adherence to the content standards of the mail class and type and packaging and handling of hazardous materials and dangerous goods.

4. Perform acceptance scans where required.

The following are examples of acceptance scans:

- Carriers scan Priority Mail Express, Priority Mail, and package tracking barcodes upon pickup from a home or business.

- Carriers scan mail collected from USPS drop boxes based on mail class, type, and extra services.

- DMUs perform a container release scan upon completion of the verification and acceptance process.

- BMEUs perform sample scans upon completion of the verification and acceptance process.

5. When accepting business mail, receive business mailings submitted to an acceptance office and perform initial verification:

- Check in business mailing.

- Verify container integrity, proper container labeling, and delivery address.

- Verify that the contents match the destination and sortation level (sorted by processing facility or ZIP Code destinations).

- Inspect against nonmachinable criteria to ensure that mail can be handled by automated mail processing machines. Nonmachinable criteria for each class of mail are specified in the DMM.

- Verify processing category: presorted letters, presorted flats, machinable letters, machinable flats, parcels, etc. 
- Verify quality and content of barcode, if applicable.

- Verify that a valid postage payment method is used. (The Mail Revenue Assurance process area provides additional information about practices related to valid types of payment.)

6. Ensure that each mailpiece is properly marked and endorsed.

Valid postage affixed for mailpiece types, classes, and extra services and valid endorsements (for example, address service requested, forwarding service requested, return service requested, and change service requested) are specified in the DMM. (The Mail Revenue Assurance process area provides additional information about mail revenue standards and practices related to postage affixed.)

7. Ensure that correct payment for postage is made.

Mailers are responsible for correct payment of postage. Postage on all mail must be fully prepaid at the time of mailing, except as specifically provided by the DMM. Acceptance personnel verify payment to ensure that it is collected according to revenue standards. Mail with insufficient, missing, or fraudulent payment is treated as discrepancy as described in MI:SG5, Manage Mail Discrepancies During Induction, and MRA:SG2.SP4, Manage Mail Revenue Discrepancies. (The Mail Revenue Assurance process area provides additional information about mail revenue standards and practices related to payment of postage.)

When accepting retail mail, verify that correct postage has been applied by the mailer or obtain payment from the mailer and apply the correct postage.

When accepting business mail, verify that the appropriate postage statement supporting documentation has been submitted and that the total piece count matches what is expected from the mailer's submitted postage statement. Review the postage statement for accuracy and completeness, and review the mailer's account to verify that funds are available and applicable fees have been paid.

8. Perform additional verification steps for specific mail types, classes, and extra services in accordance with mail induction standards.

The following are examples of additional verification steps required for Priority Mail Express:

- For Priority Mail Express Next Day Delivery, verify that the item was presented no later than the time authorized by the postmaster.

- Verify that USPS Corporate Account numbers are valid.

9. Identify discrepancies in accepted mail.

Refer to MI:SG5, Manage Mail Discrepancies During Induction, for the handling of discrepancies in accepted mail. 


\section{MI:SG2.SP3 Classify and Prioritize Mail}

Mailpieces are classified and prioritized in accordance with standards.

The classification and prioritization of mailpieces are performed in order to ensure that the USPS properly directs its operational resilience resources to the class and type of mailpieces that reflect service purchased by the mailer. Classification of mail is based on mail class and type. Prioritization of mail is based on mail class, type, and extra services requested by the mailer [DMM, pp. 6-9; POM 137.13]. Different classifications indicate different service requirements and different service expectations and handling instructions [POM, pg. 37]. In many cases, classification and prioritization are not separable and independent activities. For example, once a mailpiece is determined to be First-Class, it is automatically given a higher priority than Parcel Post.

One example of an extra service is Registered Mail. This extra service is the most secure service offered by the USPS. It incorporates a system of receipts to monitor the movement of the mailpiece from the point of induction to delivery. Registered Mail provides the sender with a mailing receipt and, upon request, electronic verification that the mailpiece was delivered or that a delivery attempt was made. Mailers can retrieve the mailpiece delivery status via the internet, by phone, or by bulk electronic file transfer for mailers who provide an electronic manifest to the USPS. USPS maintains a record of delivery (which includes the recipient's signature) for a specified period of time. Mailers may obtain a delivery record by purchasing return receipt service.

The classification and prioritization of mailpieces are key considerations in the identification of adequate resilience requirements and in the implementation of strategies to ensure the sanctity of mailpieces from the time of induction to the time of delivery. Mailpiece classification and prioritization and the corresponding mail handling processes and procedures provide a way for the USPS to designate mailpieces relative to their risks and to allow for an appropriate level of mail handling, viability, and resilience. Mailpiece classification and prioritization also ensure consistent handling of mailpieces across the USPS supply chain, including with all external entities that participate in the mail transportation and delivery lifecycle.

Each mailpiece is uniquely marked, sorted, processed, transported, and delivered to reflect its classification, prioritization, and associated extra services, in accordance with the DMM. Refer to the Mail Transportation and Mail Delivery process areas for further information.

\section{Typical Work Products}

1. Classified mailpieces, with sufficient postage affixed and postage that is not fraudulent

2. Prioritized mailpieces, with sufficient postage affixed and postage that is not fraudulent

\section{Subpractices}

1. Classify mail based on mail type and class and in accordance with standards.

2. Prioritize mail based on mail type, class, and extra services and in accordance with standards. 


\section{MI:SG2.SP4 Convey Mail to Origin Processing Facilities}

Mailpieces are conveyed from their collection location to origin processing facilities in accordance with standards.

As described in MI:SG2.SP1, Collect Mail, mailpieces are collected from a wide range of locations and entry points, including carrier pickup from homes, businesses, and mailboxes, USPS retail window mail (Post Offices or branches), contract postal units and authorized shippers, and USPS.com (online). Commercial mail in bulk and mailpiece form is collected at BMEUs and DMUs. Once mail is verified and accepted (refer to MI:SG2.SP2, Accept Mail), most retail mailpieces and some commercial mail is conveyed (transported) to processing and distribution centers (P\&DCs) for origin processing. Priority Mail pieces may be conveyed to a Priority Mail Processing Center. Commercial mail may also be conveyed to Bulk Mail Centers and directly to destination Post Offices and destination delivery units (DDUs) for origin processing prior to delivery.

Two other forms of mailing where mail is conveyed from a collection location to an origin processing facility are plant-verified drop shipments and plant-load mailings. Plant-verified drop shipments enable origin verification and postage payment for shipments transported by a mailer (or third party) at the mailer's expense, on the mailer's own or contracted vehicle, to destination USPS facilities for acceptance as mail [DMM 705.16, p 1393]. Plantload mailings consist of mail from one mailer or the combined mailings of two or more mailers loaded into one or more USPS transportation vehicles and accepted by the USPS at the mailers' plants. Plant-load mailings are typically submitted to a DMU or BMEU [POM 461.43, pg. 289]. Refer to the Mail Revenue Assurance process area for more information about these forms of mailing.

Origin processing includes all activities that are performed to prepare mail for transportation and delivery. These activities are described in the Mail Transportation process area and in the Mail Delivery process area for commercial mail that is conveyed directly to destination Post Offices and DDUs.

In most cases, mailpieces are conveyed from collection locations to origin processing facilities in a variety of containers via trucks or trailers. Mailpieces may also be conveyed via airplanes, trains, and ships. Departure/release scans are performed on all containers and trailers (and any other forms of transport) prior to mail departing a collection location. Container and trailer unload and arrival scans are performed when mail arrives at an origin processing facility.

Mailpieces that are conveyed from a collection location to an origin processing facility are subject to collection, verification, and acceptance activities as described in MI:SG2.SP1, Collect Mail, and MI:SG2.SP2, Accept Mail. In addition, such mailpieces are also subject to availability, sanctity, custody, and visibility controls as described in MI:SG4, Control Mail During Induction. 
Typical Work Products

1. Conveyed retail mailpieces

2. Conveyed commercial (business) mailpieces

\section{Subpractices}

1. Retail mail is conveyed from collection to origin processing facilities in accordance with standards.

2. Commercial (business) mail is conveyed from collection to origin processing facilities in accordance with standards.

\section{MI:SG3 Manage Risks to Mail During Induction}

Operational risks to mail during induction are identified and addressed.

The management of risk for mailpieces is the specific application of risk management tools, techniques, and methods to mail that is accepted, processed, transported, and delivered by the USPS. Due to the high volume of mail, the extensive geography over which it is delivered, and the number of organizations and individuals that participate in the mail process, there are many opportunities for mailpieces to be threatened and for risk to be realized by the USPS. Realized risk can result in indemnity claims, loss of market share, harm to the reputation of the USPS, and other consequences.

Managing mailpiece operational risks involves determining where vulnerabilities and threats to mailpieces arise and where mitigation controls must be implemented to protect mailpieces from violations of their resilience requirements-availability, sanctity, custody, and visibility. Mail risk categories include, for example,

- locations where mailpieces physically reside (containers, facilities, docks, airplanes, trucks, trains, ships, etc.). This includes risk at destination and delivery locations and facilities where it may be unsafe to deliver mail due to potential but unpredictable disruptive events (such as fires and explosions) as well as disruptive events that occur with some periodicity and predictability (such as hurricanes and winter storms).

- mail origins and destinations (domestic and international)

- mail aggregations (single pieces, sacks, pallets, etc.)

- automation used in processing Automated Parcel Processing System (APPS), MERLIN, etc.)

- personnel (USPS employees, contract postal unit employees, BMEU employees, etc.)

- mail under investigation

The identification and mitigation of risks to the successful collection of mail revenue are addressed in the Mail Revenue Assurance process area. 


\section{MI:SG3.SP1 Identify and Assess Risks to Mail During Induction}

Operational risks to mailpieces during induction are periodically identified and assessed.

Risks that can affect mail must be identified and assessed in order to actively manage the resilience of these assets and ensure that they reach their destination as intended by the mailer and in accordance with USPS standards. The identification of mailpiece risks forms a baseline from which a continuous risk management process can be established and managed.

The subpractices included in this practice are generically addressed in goals RISK:SG3 and RISK:SG4 in the Risk Management process area.

\section{Typical Work Products}

1. Mailpiece risk statements, with impact valuation

2. List of mailpiece risks, with categorization and prioritization

\section{Subpractices}

1. Determine the scope of the risk assessment for mail.

Determining which mail (type, class, extra services, type of postage, locations, etc.) to include in regular risk management activities depends on many factors, including the value of the asset to the USPS and its resilience requirements.

2. Identify risks to mailpieces.

Identification of risk for mailpieces requires an examination of all the places where mail is physically located from acceptance to delivery and based on mail type, class, and extra services as appropriate. Risks should be identified in these contexts so that mitigation and control actions are more targeted.

Operational risks for mail include

○ hazardous materials

o theft

○ unauthorized access

$\bigcirc$ inadvertent loss during transport

○ damage

- destruction from fire or natural disaster

- vulnerabilities in technologies that support the acceptance of mail

$\circ$ gaps between standards and the controls in place to meet them

3. Analyze risks to mailpieces.

4. Categorize and prioritize risks to mailpieces.

5. Assign a risk disposition to each mailpiece risk.

6. Monitor the risk and the risk strategy on a regular basis to ensure that the risk does not pose additional threat to the sanctity of mail.

7. Develop a strategy for risks that the USPS decides to mitigate. 


\section{MI:SG3.SP2 Address Risks to Mail During Induction Identified operational risks to mailpieces during induction are addressed.}

The mitigation of mailpiece risk involves the development of strategies that seek to minimize the risk to an acceptable level. This includes reducing the likelihood of risks to mailpieces, minimizing exposure to risks, developing service continuity plans to keep mailpieces viable during times of disruption, and developing recovery and restoration plans to address the consequences of realized risk.

Risk mitigation for mailpieces requires the development of risk mitigation plans (which may include the development of new mailpiece resilience controls or revision of existing controls) and implementing and monitoring these plans for effectiveness.

The subpractices included in this practice are generically addressed in goal RISK:SG5 in the Risk Management process area.

\section{Typical Work Products}

1. Mailpiece risk mitigation plans

2. List of those responsible for addressing and tracking risks

3. Status on mailpiece risk mitigation plans

\section{Subpractices}

1. Develop and implement risk mitigation strategies for all risks that have a "mitigate" or "control" disposition.

For example, a strategy to mitigate vulnerabilities in technologies that support the acceptance of mail would be to regularly perform vulnerability scanning, analysis, and resolution on those technologies. (Refer to the Vulnerability Analysis and Resolution process area for more information.)

2. Validate the risk mitigation plans by comparing them to existing strategies.

3. Identify the person or group responsible for each risk mitigation plan and ensure that they have the authority to act and the proper level of skills and training to implement and monitor the plan.

4. Address residual risk.

5. Implement the risk mitigation plans and provide a method to monitor the effectiveness of these plans.

6. Monitor risk status.

7. Collect performance measures on the risk management process. 


\section{MI:SG4 Control Mail During Induction}

Controls to protect mail during induction are established and maintained in accordance with standards.

A control is a policy, procedure, method, technology, or tool that satisfies a stated objective. Controls can be broad or specific. Broad controls typically apply universally to all processes that can affect the availability of mail, such as an accepted cultural norm that Postal Service employees turn in other Postal Service employees who steal.

Controls can be administrative, technical, or physical. Administrative controls ensure alignment to USPS management's intentions and include such actions as governance, setting policy, monitoring, auditing, and performance measurement. Technical controls are implemented through technology means. They typically exist in automated processes, manifested in software, hardware, devices, systems, and networks. Physical controls provide physical barriers to access that typically apply to people, containers, and facilities.

Refer to the Human Resource Management process area for a description of candidate controls regarding the performance and integrity of USPS personnel, where such performance may affect the protection of mail during induction (for example, resilience as a job responsibility).

Refer to the People Management process area for a description of candidate controls regarding the availability of USPS personnel to perform mail induction (for example, support to staff during disruptive events).

Refer to the Organizational Training and Awareness process area for a description of candidate controls regarding the preparedness and readiness of USPS personnel to perform mail induction (for example, adequate training).

\section{MI:SG4.SP1 Control Availability of Mail During Induction}

Controls are established and maintained to assure availability of mailpieces during induction in accordance with standards.

Availability is the requirement that mailpieces be accessible to all authorized citizens in a timely fashion as determined by the mail class and extra services. To achieve that requirement, mail must not be lost, stolen, or unnecessarily delayed. Once mail enters the mailstream, it must follow normal processing and transfer sequences and service standards. It must not be removed from the mailstream except as allowed by laws and standards such as ASM 274.3, Permissible Detention of Mail.

Loss or theft of Insured Mail, Registered Mail, COD, or Priority Mail Express mailpieces may result in indemnity claims being filed by the mailers or addressees [POM 146]. Failure to meet service standards for Priority Mail Express may result in refunds being issued to mailers. 
Mail availability controls should satisfy standards, policies, operating procedures, and other specifications that relate to and affect the availability of mail, provide confidence that they are being followed, and reduce the risks that would result in mail being unavailable. Specific availability controls are applied to mail products, such as insurance against loss or damage for Priority Mail Express [DMM 503.1.1.7]. They also include in-process controls that happen at specific points in the mailstream lifecycle. For example, visibility scans such as the Holotrack scan for Priority Mail Express and the chain of scans and/or signatures from the point of acceptance to delivery for Registered Mail affirm that the mailpieces are still in the mailstream and show whether they've been delayed.

Administrative controls for limiting delay of mail might include capacity management plans, alternate routes, and having separate processing areas for high-volume destinations. An example of an administrative control for protecting mail from theft is the policy requiring that all individuals who are not authorized on-duty Postal Service employees and authorized contractors must be properly escorted [ASM 273.121]. Examples of technical controls are closed circuit television systems and electronic card access control systems. Physical controls for mail availability include picture IDs, locks used to secure collection and relay boxes, facility alarm systems, and locks and numbered tin band seals on trucks that are transporting mail. Locking doors leading from Post Office box or service lobbies to workroom areas and keeping exterior lobby windows clear of obstruction to maximize observation of the lobby area are physical measures taken to help prevent robbery [ASM 226.1].

The subpractices included in this practice are generically addressed in the Controls Management process area.

\section{Typical Work Products}

1. Mail availability controls (including the responsible party)

2. Traceability matrix of standards, policies, operating procedures, and other specifications and mail availability controls

3. Mail availability control gaps

4. Mail availability control updates

5. Discrepancies identified by mail availability controls

\section{Subpractices}

1. Establish and implement mail availability controls in accordance with standards.

2. Confirm or assign responsibility for implementing availability controls.

Confirmation is required for existing and updated controls. Assignment is required for new controls.

3. Develop a bidirectional traceability matrix that maps standards and availability controls. 
4. For standards that are not addressed by availability controls, identify and manage the risks associated with control gaps as described in MI:SG3, Manage Risks to Mail During Induction.

5. Regularly review and assess the effectiveness of availability controls and update or retire controls as needed.

As standards, services, processes, and technologies change, gaps and redundancies may arise between mail availability standards and the controls established to satisfy them.

(Refer to CTRL:SG4.SP1 for further information about periodically assessing and adjusting controls.)

6. Identify discrepancies identified by mail availability controls.

Refer to MI:SG5, Manage Mail Discrepancies During Induction, for the handling of discrepancies identified by mail availability controls.

\section{MI:SG4.SP2 Control Sanctity of Mail During Induction}

Controls are established and maintained to assure sanctity of mailpieces during induction in accordance with standards.

Sanctity is the requirement that mailpieces be protected from damage, alteration of original content, disclosure, and destruction. It includes the principle of the "sanctity of the seal" for certain classes of mail, which protects such mailpieces against unauthorized access to their contents. Sanctity encompasses the information resilience requirements of integrity (keeping the asset in the condition intended by the owner) and confidentiality (ensuring that the asset is accessible only to authorized people, processes, and devices) for mailpieces.

Damage to Insured Mail, Registered Mail, COD, or Priority Mail Express articles may result in indemnity claims being filed by the mailers or addressees [POM 146].

Mail sanctity controls should satisfy standards, policies, operating procedures, and other specifications that relate to and affect the sanctity of mail, provide confidence that they are being followed, and reduce the risks that would result in mail sanctity being violated.

Broad controls typically apply universally to all processes that can affect the sanctity of mail, such as USPS Standards of Conduct that are impressed upon employees by supervisors and sustained by the influence of the culture. Specific sanctity controls are applied to mail products, such as use of registry cages inside Postal Service facilities to limit access of Registered Mail to authorized individuals. They also include in-process controls that happen at specific points in the mailstream lifecycle, such as the use of numbered metal seals on the doors of Postal Service trucks to ensure that the doors have not been opened between locations.

Administrative controls for sanctity include record controls and specification of approved manufacturers and models for mail receptacles in apartment houses [POM 632.628]. An example of an administrative control for protecting mail from damage is the USPS policy to 
containerize all classes of mail wherever possible [POM 573.1, pg. 356]. There are no technical controls for mail sanctity, although mail processing equipment does halt upon the detection of misfed mail, which has a higher chance of occurring with an unsealed piece than a sealed piece. Physical controls for mail sanctity include keys for mail receptacles in apartment houses [POM 632.627] and the use of concealed containers, robust plastic containers used to ship registered mail and other mail of value on airplanes. Controls that protect mail against theft also serve to protect mail against unauthorized access with the intent of disclosure or destruction, such as using locks to secure collection and relay boxes [ASM 278.11].

The subpractices included in this practice are generically addressed in the Controls Management process area.

\section{Typical Work Products}

1. Mail sanctity controls (including the responsible party)

2. Traceability matrix of standards, policies, operating procedures, and other specifications and mail sanctity controls

3. Mail sanctity control gaps

4. Mail sanctity control updates

5. Discrepancies identified by mail sanctity controls

\section{Subpractices}

1. Establish and implement mail sanctity controls for mailpieces in accordance with standards.

2. Confirm or assign responsibility for implementing sanctity controls.

Confirmation is required for existing and updated controls. Assignment is required for new controls.

3. Develop a bidirectional traceability matrix that maps standards and sanctity controls.

4. For standards that are not addressed by sanctity controls, identify and manage the risks associated with control gaps as described in MI:SG3, Manage Mail Risk During Induction.

5. Regularly review and assess the effectiveness of sanctity controls and update or retire controls as needed.

As standards, services, processes, and technologies change, gaps and redundancies may arise between mail sanctity standards and the controls established to satisfy them. (Refer to CTRL:SG4.SP1 for further information about periodically assessing and adjusting controls.)

6. Identify discrepancies identified by mail sanctity controls.

Refer to MI:SG5, Manage Mail Discrepancies During Induction, for the handling of discrepancies identified by mail sanctity controls. 


\section{MI:SG4.SP3 Control Custody of Mail During Induction}

Controls are established and maintained to assure custody of mailpieces during induction in accordance with standards.

Custody of mail begins when USPS facilities (such as letter collection receptacles and parcel depositories at Post Offices) and USPS personnel (such as mail carriers) collect and take physical possession of a mailpiece (refer to MI:SG2.SP1, Collect Mail, for a list of mail entry points). As a result, custody of mail can commence prior to and also during mail verification and acceptance by USPS acceptance personnel. Custody ends or terminates when mail is delivered to the addressee or their designee (personal mailbox, mail room, etc.) as described in the Mail Delivery process area. If the mail is undeliverable, custody terminates when the sender receives the mailpiece on return. A sender may be the individual who sent the mailpiece, their physical mailbox, the designated mail room for their organization that accepts mail on their behalf, etc. [DMM, pg. 1175].

In addition to mail class and type, extra services are available that provide proof of mailing, proof of delivery, or indemnification for loss or damage. Because records are kept concerning each mailpiece receiving these extra services, such mail is called accountable mail [POM 137.441]. Accountable mail has more custody requirements and controls than other classes and types of mail such as Priority or First-Class Mail without extra services. Accountable mail is mail that requires the signature of the addressee or addressee's agent upon receipt to provide evidence of delivery or indemnification for loss or damage.

Examples of accountable mail include [POM 137.44; DMM 503, 505, 508; Pub 32]

- Certified Mail

- Registered Mail

- Collect on Delivery (COD)

- return receipt

- merchandise return service

- customs duty

- postage due

- Priority Mail Express

- signature confirmation

- mail insured for more than $\$ 200$

Custody of mail may also be established by the type of postage that is affixed to each mailpiece. Types of postage include stamps, prepaid stationery and packaging, postage evidencing systems (which include meter imprints and PC postage products such as Click-NShip and stamps.com), and permit imprint mail (refer to the Mail Revenue Assurance process area for more details). Meter imprint mail may contain postage that includes information based indicia (IBI). The information contained in IBI and barcodes may be used to establish and manage custody of mailpieces. Mailpieces may also contain postage that 
includes an IMb. The information contained in IMbs may be used to establish and manage custody of mailpieces.

Business mailers can expedite service by using their own transportation vehicles to move mail they are originating from their DMU to the origin postal facility within a designated ZIP Code area [DAR, pg. 8]. Even though mailers are using their own transportation vehicles, the USPS accepts custody of mail at the DMU.

For satisfying standards, policies, operating procedures, and other specifications that relate to and affect the custody of mail, the focus is on the controls that demonstrate the satisfaction of such standards, provide confidence that they are being followed, and reduce the risks that would result in the inability to maintain the custody of mailpieces as required. The custody of mail is accomplished by ensuring that adequate controls are in place to allow mailers to confirm that their mail is in the immediate charge and control of authorized USPS personnel throughout the mail lifecycle, from collection to delivery. The ability of mailers to determine who has custody of their mail varies based on mail class, type, extra services, tracking numbers, and postage such as Registered Mail and Certified Mail markings and labels.

A unique tracking number can be associated with specific classes and types of mail. Mail for which tracking numbers are assigned include Certified Mail, Registered Mail, Priority Mail Express, delivery confirmation, and signature confirmation. Mailers receive a tracking number for Priority Mail automatically if they a use PC Postage system such as Click-N-Ship, or they can buy one at a Post Office.

Acceptance personnel located at acceptance offices are responsible for verifying that the mail presented to them meets custody standards for the mail class, type, and extra services.

Registered Mail is the most secure transportation and delivery service offered by the USPS. The rules and procedures for handling valuable Registered Mail, such as shipments of cash, require that every transfer of custody is documented by chain-of-custody receipts so that individual accountability can be determined at all times. Registered Mail has the most rigorous custody requirements and controls, including the following [DMM 503.2.2.1, pg. 769]:

- A system of receipts monitors the movement of the mail from the point of acceptance to delivery.

- The sender is provided with a mailing receipt and, upon request, electronic verification that an article was delivered or that a delivery attempt was made.

- USPS maintains a record of delivery (which includes the recipient's signature) for a specified period of time.

- Mailers may obtain a delivery record by purchasing return receipt service. Collect on delivery, delivery confirmation, and signature confirmation services are also available [DMM 503.2.2.1, pg. 769]. 
- Acceptance employees must keep Registered Mail in a secure place (locked drawer, cabinet, safe, or registry section) until accountability is transferred hand-to-hand to the designated dispatch employee. Access to the item must be limited to a single individual. Shared access is strictly prohibited. Individual employee accountability of Registered Mail must be maintained at all times.

- Registered Mail is transferred from one individual to another on the appropriate form and must be signed for by the receiving individual at the time of transfer. Additional transfer of accountability standards are described in Handbook DM-901 Registered Mail [HB DM-901].

Mailpieces that are not marked in accordance with custody standards and whose custody postage does not sufficiently reflect the type, class, extra services, and attributes of the mailpiece to which they are affixed are handled as discrepancies as described in MI:SG5, Manage Mail Discrepancies During Induction.

The identification and mitigation of mail custody risks that may result from incorrect or missing mail visibility postage are addressed in MI:SG3, Manage Mail Risk During Induction, and in the Risk Management process area.

\section{Typical Work Products}

1. Mail custody controls (including the responsible party)

2. Traceability matrix of standards, policies, operating procedures, and other specifications and mail custody controls

3. Mail custody control gaps

4. Mail custody control updates

5. Discrepancies identified by mail custody controls

\section{Subpractices}

1. Establish and implement mail custody controls in accordance with standards.

Ensure that controls are adequate to identify mail custody postage that is insufficient, fraudulent, or any additional discrepancies. Examples of such controls could include

- manual inspection

- confirmation that a specific mailing and its companion electronic documentation is (or is not) associated with a specific and authorized mailer

- the use of postage scanning systems (such as the Advanced Facer Canceler System (AFCS), Delivery Bar Code Sorter (DBCS), APPS, and Passive Adaptive Scanning System (PASS); scans from some of these systems are imported into the Total Revenue Protection (TRP) system for further analysis) 
2. Confirm or assign responsibility for implementing custody controls.

Confirmation is required for existing and updated controls. Assignment is required for new controls.

3. Develop a bidirectional traceability matrix that maps standards and custody controls.

4. For standards that are not addressed by custody controls, identify and manage the risks associated with controls gaps as described in MI:SG3, Manage Risks to Mail During Induction.

5. Regularly review and assess the effectiveness of custody controls and update or retire controls as needed.

As standards, services, processes, and technologies change, gaps and redundancies may arise between mail custody standards and the controls established to satisfy them. (Refer to CTRL:SG4.SP1 for further information about periodically assessing and adjusting controls.)

6. Identify discrepancies identified by mail custody controls.

Refer to MI:SG5, Manage Mail Discrepancies During Induction, for the handling of discrepancies identified by mail custody controls.

\section{MI:SG4.SP4 Control Visibility of Mail During Induction}

Controls are established and maintained to assure visibility of mailpieces during induction in accordance with standards.

Visibility of mail from the time and location of mail acceptance to the time and location of mail delivery is based on mail class, type, extra services, and postage affixed including barcodes. Mail visibility standards are primarily specified in the DMM and the POM. Informative material on mail visibility for Intelligent Mail is available on the USPS and Rapid Information Bulletin Board System (RIBBS) [5] websites.

Visibility of mail may also be established by the type of postage that appears on each mailpiece. Types of postage include stamps, prepaid stationery and packaging, postage evidencing systems (which include meter imprints and PC postage products such as Click-NShip and stamps.com), and permit imprint mail (refer to the Mail Revenue Assurance process area for more details). Meter imprint mail may contain postage that includes IBI. The information contained in IBI and barcodes may be used to establish and manage visibility of mailpieces. Mailpieces may also contain postage that includes an IMb. The information contained in IMbs may be used to establish and manage visibility of mailpieces.

For satisfying standards, policies, operating procedures, and other specifications that relate to and affect the visibility of mail, the focus is on the controls that demonstrate the satisfaction of such standards, provide confidence that they are being followed, and reduce the risks that would result in inadequate or missing visibility of mailpieces as required. The visibility of mail is accomplished by ensuring that adequate controls are in place to allow 
mailers to follow the progress of their mail through the mail lifecycle, from acceptance to delivery. The ability of mailers to track their mail varies based on mail class, type, extra services, tracking numbers, and postage such as IBI and IMb.

Accountable mail has more visibility requirements and controls than other classes and types of mail such as Priority or First-Class Mail without extra services. Accountable mail is mail that requires the signature of the addressee or addressee's agent upon receipt to provide evidence of delivery or indemnification for loss or damage. Accountable mail includes Priority Mail Express and extra services such as Certified Mail, Collect on Delivery, mail insured for more than $\$ 200$, Registered Mail, return receipt, and signature confirmation [Pub 32].

A unique tracking number can be associated with specific classes and types of mail. Mail for which tracking numbers are assigned include Certified Mail, Registered Mail, Priority Mail Express, delivery confirmation, and signature confirmation. Mailers receive a tracking number for Priority Mail automatically if they a use PC Postage system such as Click-N-Ship, or they can buy one at a Post Office.

Acceptance personnel located at acceptance offices are responsible for verifying that the mail presented to them meets visibility standards for the mail class, type, and extra services. Intelligent Mail products and services use machine-readable barcodes to uniquely identify mail, which allows large business mailers to track their mail. In addition, this information helps the USPS and businesses better manage their resources, reduce operating and marketing expenses, adapt to market conditions, increase efficiencies, and be more responsive to customers. Barcodes also provide the ability to perform operational service analytics, generate customer level data for pricing, and assure revenue [Cochrane 2012], [8], [9].

The USPS Intelligent Mail program [8] requires the use of a unique, trackable barcode applied to letters, postcards and flat mailpieces (First-Class, Periodicals, Standard Mail), trays, sacks, and containers, such as pallets, as well as the submission of electronic mailing documentation. Currently defined barcodes include the following [Pub 32]:

- $\mathrm{IMb}$ for letters and flats

- IMpb for packages

- Intelligent Mail tray barcode (IMtb) for trays and sacks

- Intelligent Mail Container barcode (IMcb) for containers and pallets

The suite of IMbs identify the owner and sender of a mailpiece, identify the mailpiece or the mail aggregate (multiple mailpieces that are aggregated into a single mailing at the bundle, tray, sack, or container level), encode product or service requests on mailpieces or mail aggregates, and provide sorting and routing information [9].

Mailers can track their Intelligent Mail by using the IMb tracking service. Mailers identify their mail by placing an IMb on their letter and flat mailpieces. As mailpieces with an IMb 
are processed on USPS sorting equipment, records are created containing the IMb, processing facility, operation number, and processing date and time. These records are electronically forwarded to mailers or available on a USPS website for manual download [10].

Scanning is a fundamental control for mail visibility. Scan events (also referred to as track events) for mail based on mail type, class, extra services, and postage may include all or some of the following [Cochrane 2012]:

- electronic shipping information received from the mailer

- mail acceptance

- mail departs Post Office/BMEU (dispatched to sort facility)

- mail arrives at sort facility

- mail processed through USPS sort facility (enroute)

- mail departs USPS sort facility

- mail arrives at USPS sort facility (destination)

- mail processed through delivery USPS sort facility (enroute)

- mail departs USPS sort facility

- mail arrives at Post Office

- mail processing complete

- mail out for delivery

- mail delivered

The objectives for the visibility of Intelligent Mail include a legible, scannable barcode on every mailpiece, visibility of mailpieces from acceptance to delivery, 10 to 12 tracking events per mailpiece, and scan performance that is $99 \%$ accurate and available in real time [Cochrane 2012].

Mailpieces that are not marked in accordance with visibility standards and whose visibility postage does not sufficiently reflect the type, class, extra services and attributes of the mailpiece to which they are affixed are handled as discrepancies, as described in MI:SG5, Manage Mail Discrepancies During Induction.

The identification and mitigation of mail visibility risks that may result from incorrect or missing mail visibility postage are addressed in MI:SG3, Manage Mail Risk During Induction, and in the Risk Management process area.

\section{Typical Work Products}

1. Mail visibility controls (including the responsible party)

2. Traceability matrix of standards, policies, operating procedures, and other specifications and mail visibility controls

3. Mail visibility control gaps

4. Mail visibility control updates

5. Discrepancies identified by mail visibility controls 


\section{Subpractices}

1. Establish and implement mail visibility controls in accordance with standards.

Ensure that controls are adequate to identify mail visibility postage that is insufficient or fraudulent, or any additional discrepancies. Examples of such controls could include

○ manual inspection

- confirmation that a specific mailing and its companion electronic documentation is (or is not) associated with a specific and authorized mailer

- the use of postage scanning systems (such as the Advanced Facer Canceler System (AFCS), Delivery Bar Code Sorter (DBCS), Automated Parcel Processing System (APPS), and Passive Adaptive Scanning System (PASS); scans from some of these systems are imported into the Total Revenue Protection (TRP) system for further analysis)

2. Confirm or assign responsibility for implementing visibility controls.

Confirmation is required for existing and updated controls. Assignment is required for new controls.

3. Develop a bidirectional traceability matrix that maps standards and controls.

4. For standards that are not addressed by controls, identify and manage the risks associated with control gaps as described in MI:SG3, Manage Mail Risk.

5. Regularly review and assess the effectiveness of controls and update or retire controls as needed.

As standards, services, processes, and technologies change, gaps and redundancies may arise between mail visibility standards and the controls established to satisfy them. (Refer to CTRL:SG4.SP1 for further information about periodically assessing and adjusting controls.)

6. Identify discrepancies identified by mail visibility controls.

Refer to MI:SG5, Manage Mail Discrepancies During Induction, for the handling of discrepancies identified by mail visibility controls.

\section{MI:SG5 Manage Mail Discrepancies During Induction}

Discrepancies during the induction of mail are identified and addressed.

As stated in MI:SG1.SP1, Establish Standards for Mail Induction, mail induction standards define mailability-the eligibility of an item or mailpiece to be accepted into the mailstream because it meets size, weight, and other preparation criteria and its contents are not prohibited by law as mail [Pub 32]. The DMM specifies induction standards for all types and classes of mail. Non-compliance with these standards constitutes a mail discrepancy. Non-compliance with standards for the availability, sanctity, custody, and visibility of mail (refer to MI:SG1.SP1) should also result in the identification of a mail discrepancy. 
Mail discrepancies result from intentional and fraudulent acts and from inadvertent omission or error. Discrepancies may be caused by mailers, USPS personnel or systems, or people using the mail to perpetrate criminal activity. Mail discrepancies can be innocuous and go unnoticed or can significantly impact the ability of the USPS to fulfill its mission. To ensure the operational resilience of accepted mail, the USPS must maximize its opportunities to identify discrepancies before mail is formally accepted. However, because not all mail discrepancies can be prevented, the USPS must have the capability to identify mail discrepancies during mail verification and acceptance and respond appropriately as defined in this specific goal. (The management of mail discrepancies during transportation and delivery is addressed in the Mail Transportation process area and the Mail Delivery process area, respectively. The management of mail revenue discrepancies and mail revenue fraud is discussed in the Mail Revenue Assurance process area.)

In order to effectively resolve mail discrepancies, the USPS must develop and maintain plans for managing mail discrepancies (identify, analyze, open an investigation, resolve, etc.), including having a structure and supporting systems for discrepancy event detection, reporting, logging, and tracking, and for collecting and storing discrepancy evidence.

The analysis of mail discrepancy events, their declaration as incidents, and the appropriate USPS response are addressed in the Incident Management and Control process area.

\section{MI:SG5.SP1 Establish and Maintain Mail Discrepancy Plans for Induction} Plans and procedures for managing mail discrepancies during induction are established and maintained.

The USPS must develop plans and procedures for handling mail discrepancies of various types. Plans and procedures should reflect USPS strategies, objectives, critical success factors, risks, and tactics where possible and appropriate, as well as standards and applicable laws. These factors should determine the USPS approach for identifying, analyzing, responding to, and resolving mail discrepancies.

Specifically, the USPS must plan for how it will

- identify mail discrepancy events (e.g., through a problem reporting activity or through monitoring)

- analyze these events and determine an appropriate response (e.g., opening an investigation)

- prioritize events, in case decisions must be made about which events to respond to, due to limited resources

- respond to events (e.g., a local response or a coordinated headquarters response)

- close events

- structure and staff the plan (by assigning individuals or groups to specific roles or by creating a specialized response team or similar group)

The USPS should develop and document its plans and procedures for handling mail discrepancies (in the DMM, POM, or elsewhere) and outline the specific objectives of the 
plan for each type of mail discrepancy. The objectives of the plan should be translated into specific actions and assigned to individuals or groups to be performed when a discrepancy occurs.

\section{Typical Work Products}

1. Mail discrepancy plans and procedures

2. Updates to mail discrepancy plans and procedures

\section{Subpractices}

1. Define and document mail discrepancy plans and procedures.

2. Review plans and procedures with relevant stakeholders and get their commitment.

3. Revise mail discrepancy plans and procedures as necessary.

Refer to IMC:SG5, Establish Incident Learning, for guidance on performing postdiscrepancy reviews, capturing lessons learned from handling mail discrepancies, and using these to inform revisions to mail discrepancy plans and procedures.

MI:SG5.SP2 Identify and Address Mail Discrepancies During Induction Mail discrepancies during induction are identified and addressed in accordance with plans and procedures.

The USPS must be able to identify mail discrepancy events as they occur, as well as to determine when an event or a series of events constitutes an incident that requires further handling and escalation (e.g., a coordinated and planned response, such as an investigation). Identifying events in a timely manner may help to contain their operational impact and the cost of addressing them.

Some incidents, such as mail damaged in transit and mail collected but never delivered, will be reported to the USPS by mailers and other external individuals and entities.

Occurrences of non-compliance with mail induction standards in the following categories are identified and addressed as mail discrepancies:

- dimensions and weights

- elements on the face of mailpieces

- addressing

- packaging and containers

- nonmailable matter, including certain dangerous and hazardous goods

- postage affixed, labels, and barcodes

- forms, permits, and documentation

- $\quad$ signatures

- quantity and bundling 
Examples of availability, sanctity, custody, and visibility discrepancies are

- failure to achieve end-to-end service standards

- failure to execute chain-of-custody rules

- theft of mailpieces from collection boxes

- mail damaged by malfunction of mail sorting equipment

- a mailpiece being opened and examined by an unauthorized employee

- loss of a mailpiece because of negligence

Mailpieces that are not marked in accordance with visibility standards and whose visibility postage does not sufficiently reflect the type, class, extra services and attributes of the mailpiece to which they are affixed are identified and addressed as mail discrepancies.

Discrepancies resulting from non-compliance with mail induction standards for prices, fees, and payment methods are addressed in MRA:SG2.SP4, Manage Mail Revenue Discrepancies. Instances of mail revenue fraud are addressed in MRA:SG3.SP5, Investigate Fraudulent Postage, Postage Affixed, and Forms of Payment.

Typical Work Products

1. Discrepancy events identified during the induction of mail

\section{Subpractices}

1. Detect and report mail induction discrepancy events (as described in IMC:SG2, Detect Events).

Such events are identified during mail collection and acceptance and in the execution of mail availability, sanctity, custody, and visibility controls.

2. Address mail induction discrepancy events according to mail discrepancy plans. 


\section{Mail Induction Process Area References}

[ASM 2012] Administrative Support Manual, Issue 13, July 1999, with November 2012 updates.

[Cochrane 2012] Cochrane, James. "USPS End-to-End Visibility: Using Data to Drive Performance and Network Optimization," PostCom, March 15, 2012.

http://www.postcom.org/public/webinars/PostCom\%20Mar\%2015 v7\%20Cochrane\%2020 12.pdf

[DMM] Domestic Mail Manual, November 2011. Updated online at http://pe.usps.com/text/dmm300/dmm300 landing.htm; Quick Service Guide 800 Glossary of Postal Terms and Abbreviations in the DMM, November 2012.

http://pe.usps.com/text/qsg300/q800.htm.

[DAR] “Mail Entry \& Payment Technology: Commercial Mail Acceptance Transformation. Decision Analysis Report (DAR) Business Case," Version 0.9, Draft as of 2/10/2012.

[e-CFR] U. S. Government Printing Office. Electronic Code of Federal Regulations e-CFR. Title 39: Postal Service. Current as of June 4, 2013. http://www.ecfr.gov/cgi-bin/text$i d x$ ? $=e c f r \& s i d=5836239 c d 7 a f 4936 e 8 a e e 32 b 6 b 94 c 241 \&$ rgn=div5\&view=text\&node=39:1.0. 1.3.13\&idno=39

[HB DM-901] United States Postal Service. Handbook DM-901 Registered Mail, September 2004. http://www.nalc.org/depart/cau/pdf/manuals/dm901.pdf

[Mehravari 2013] Mehravari, Nader. Mail entry points diagram (from multiple sources), April 2013.

[POM] Postal Operations Manual, POM Issue 9, July 2002; updated as of December 2011 at http://uspsmanuals.lettercarriernetwork.info/POM9.pdf

[Pub 28] United States Postal Service. Publication 28 Postal Addressing Standards, April 2012. http://pe.usps.com/text/pub28/welcome.htm

[Pub 32] United States Postal Service. Publication 32 Glossary of Postal Terms, April 2011. http://about.usps.com/publications/pub32.pdf

[Pub 52] United States Postal Service. Publication 52 Hazardous, Restricted, and Perishable Mail, May 2012. http://pe.usps.com/text/pub52/welcome.htm

[Pub 97] United States Postal Service. Publication 97 Express Mail Manifesting System Business and Technical Guide, January 2012.

http://ribbs.usps.gov/mac/documents/tech guides/pubs/pub97.pdf

[Pub 399] United States Postal Service. Publication 399 Pickup Services Field Guide, October 2010.

[Pub 417] United States Postal Service. Publication 417 Nonprofit Standard Mail Eligibility, March 2006. http://pe.usps.com/text/pub417/welcome.htm 
[Pub 430] United States Postal Service. Publication 430 All About Merlin, June 2005. http://about.usps.com/publications/pub430/welcome.htm

[UPU 2012] Universal Postal Union. Postal security standards - General security measures, S58-1 pre-publication A, February 2012.

[USPS 2009] United States Postal Service. Intelligent Mail Barcode Specification USPS-B3200. March 11, 2009.

https://ribbs.usps.gov/intelligentmail mailpieces/documents/tech guides/SPUSPSG.pdf

[USPS 2012] United States Postal Service. A Guide to Intelligent Mail for Letters and Flats v7.8.6, November 2012.

http://ribbs.usps.gov/intelligentmail guides/documents/tech guides/GuidetolntelligentMai ILettersandFlats.pdf

\section{Websites}

[1] Quick Service Guide 503 - Additional Services - Extra Services.

http://pe.usps.com/text/qsg300/Q503.htm

[2] http://www.merriam-webster.com/dictionary

[3] http://dictionary.reference.com

[4] http://pe.usps.com/

[5] https://ribbs.usps.gov/

[6] Quick Service Guide 110 - Retail Letters, Flats, and Parcels - Express Mail http://pe.usps.com/text/qsg300/Q110.htm

[7] Quick Service Guide 210 - Commercial Parcels - Priority Mail Express http://pe.usps.gov/text/qsg300/Q210.htm\#1009536

[8] https://www.usps.com/business/intelligent-mail.htm

[9] https://ribbs.usps.gov/index.cfm?page=intelligentmail

[10] https://mailtracking.usps.com/mtr/landing/resources/confirm/landingHowWorks.jsp; also IMb Tracing FAQs

[11] http://about.usps.com/postal-bulletin/welcome.htm

[12] http://www.law.cornell.edu/uscode/text/39/404

[13] http://www.law.cornell.edu/uscode/text/18/part-l/chapter-83 


\section{References}

[Allen 2014a] Allen, Julia H.; Crabb, Gregory; Curtis, Pamela D.; Lin, Sam; Mehravari, Nader; \& Wilkes, Dawn. CERT Resilience Management Model Mail-Specific Process Areas: International Mail Transportation, Version 1.0 (CMU/SEI-2014-TN-012). Software Engineering Institute, Carnegie Mellon University, August 2014. http://resources.sei.cmu.edu/library/asset-view.cfm?assetID=296395

[Allen 2014b] Allen, Julia; Crabb, Gregory; Curtis, Pamela, D.; Mehravari, Nader; \& White, David W. CERT Resilience Management Model Mail-Specific Process Areas: Mail Revenue Assurance, Version 1.0 (CMU/SEI-2014-TN-011). Software Engineering Institute, Carnegie Mellon University, August 2014. http://resources.sei.cmu.edu/library/assetview.cfm?assetID $=296378$

[Caralli 2011] Caralli, Richard A.; Allen, Julia H.; White, David W. CERT ${ }^{\circledast}$ Resilience Management Model: A Maturity Model for Managing Operational Resilience. AddisonWesley, 2011. http://resources.sei.cmu.edu/library/asset-view.cfm?assetid=30375

[Crabb 2012] Crabb, Greg. U.S. "Postal Inspection Service Use of the CERT Resilience Management Model" (CERT podcast). Software Engineering Institute, Carnegie Mellon University, August 2012. http://resources.sei.cmu.edu/library/asset-view.cfm?assetid=34576

[Crabb 2014] Crabb, Greg; Allen, Julia H.; Mehravari, Nader; \& Curtis, Pamela D. Improving the Security and Resilience of U.S. Postal Service Mail Products and Services Using the CERT ${ }^{\circ}$ Resilience Management Model (CMU/SEI-2013-TN-034). Software Engineering Institute, Carnegie Mellon University, January 2014. http://resources.sei.cmu.edu/library/assetview.cfm?assetid $=77277$

[Joch 2013] Joch, A. "Operational Resilience: Bringing Order to a World of Uncertainty." Federal Computer Week, July 8, 2013. http://fcw.com/articles/2013/07/08/exectechoperational-resilience.aspx 


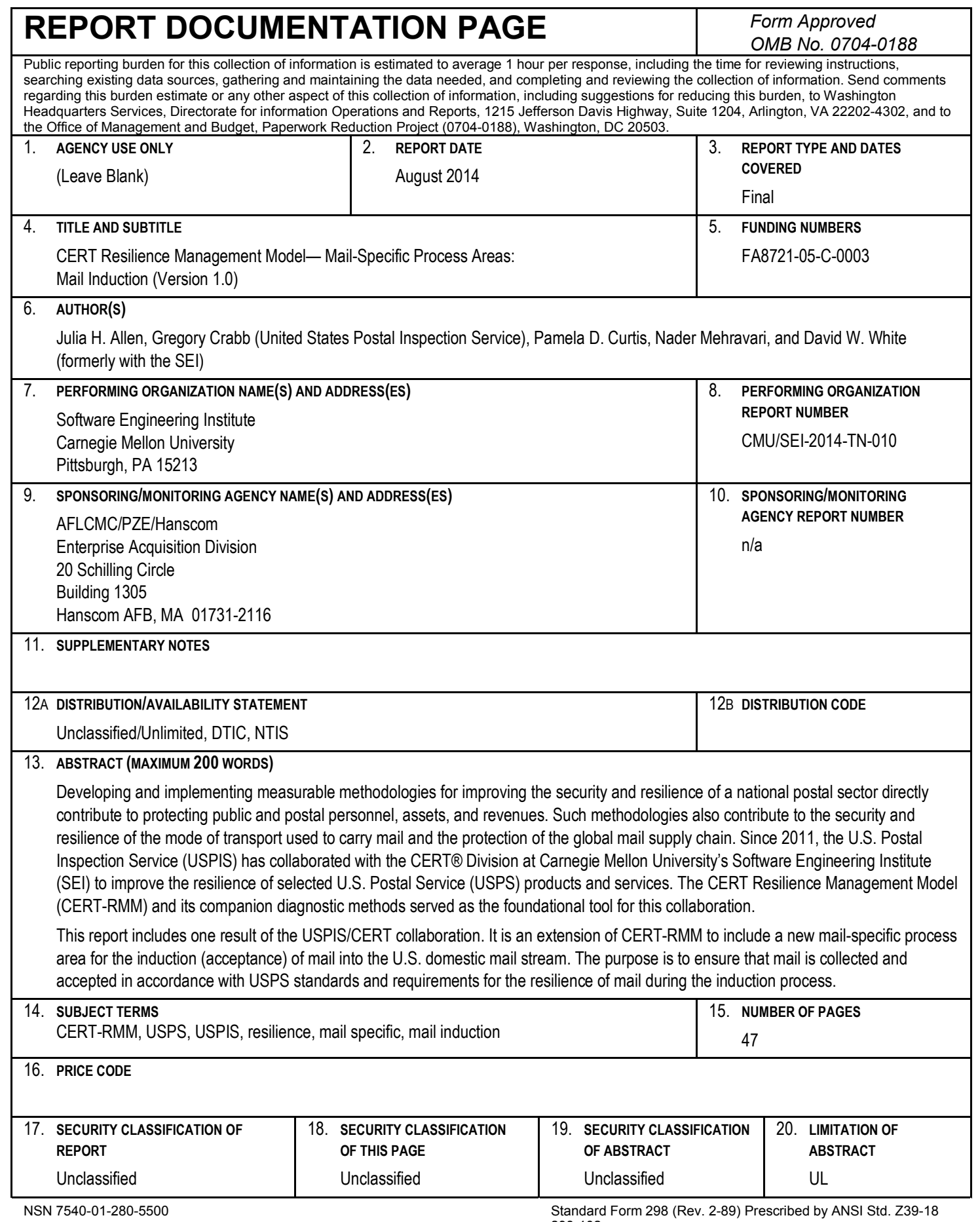

